\title{
Iron Sucrose Impairs Phagocytic Function and Promotes Apoptosis in Polymorphonuclear Leukocytes
}

\author{
Hirohito Ichii Yuichi Masuda Tania Hassanzadeh Mateen Saffarian \\ Sastry Gollapudi Nosratola D. Vaziri \\ Departments of Surgery and Medicine, University of California, Irvine, Calif., USA
}

\section{Key Words}

Iron • Infection • Inflammation • Immune deficiency •

Anemia $\cdot$ End-stage renal disease $\cdot$ Dialysis

\begin{abstract}
Background: With the recent implementation of bundling reimbursement policy, the use of intravenous (IV) iron preparations for the management of anemia in the end-stage renal disease (ESRD) population has dramatically increased. Iron overload increases the risk of infections in individuals with or without kidney disease. IV iron administration in ESRD patients impairs bacteriocidal capacity of polymorphonuclear leukocytes (PMNs) against Escherichia coli. These preparations consist of an elemental iron core and a carbohydrate shell. In addition to the iron core, the carbohydrate shell may affect PMNs. We therefore examined the effect of iron sucrose, a commonly used preparation, on phagocytic capacity of PMNs from a group of normal individuals against Gram-positive (Staphylococcus aureus) and Gram-negative (E. coli) bacteria. Methods: Iron sucrose was added to heparinized blood samples at pharmacologically-relevant concentrations and incubated for 4 and $24 \mathrm{~h}$ at $37^{\circ} \mathrm{C}$ to simulate in vivo condition. Blood samples mixed with equal volume of saline solution served as controls. To isolate the effects of
\end{abstract}

the carbohydrate shell, blood samples were co-treated with the iron chelator, desferrioxamine. Results: Iron sucrose caused significant PMN apoptosis and dose-dependent suppression of phagocytic function against both Gram-positive and Gram-negative bacteria. These abnormalities were prevented by desferrioxamine which precluded contribution of the carbohydrate shell to the PMN dysfunction. Conclusions: At pharmacologically-relevant concentrations, iron sucrose promotes apoptosis and inhibits phagocytic activities of PMNs. The deleterious effect of iron sucrose is mediated by its elemental iron core, not its carbohydrate shell, and as such may be shared by other IV iron preparations.

Copyright $\odot 2012$ S. Karger AG, Basel

\section{Introduction}

Bacterial infections are the second most common cause of death in patients with end-stage renal disease (ESRD) [1-3]. This is largely due to the deficient immune response in uremia $[1,4]$ which is caused by: dysfunction of the antigen-presenting cells [4-6], depletion of the

H. Ichii and Y. Masuda contributed equally to this work.

\section{KARGER}

Fax +41613061234

E-Mail karger@karger.ch

www.karger.com
(C) 2012 S. Karger AG, Basel

0250-8095/12/0361-0050\$38.00/0

Accessible online at:

www.karger.com/ajn
N.D. Vaziri, MD, MACP

Division of Nephrology and Hypertension, Suite 400, City Tower

University of California, Irvine Medical Center

101 The City Drive, Orange, CA 92868 (USA)

Tel. +1 714456 5142, E-Mail ndvaziri@uci.edu 
dendritic cells [7], diminished numbers and reduced antibody-producing capacity of B lymphocyte [4, 8-10], increased T-cell turnover and apoptosis culminating in depletion of naive and central memory CD $4+$ and $\mathrm{CD} 8+\mathrm{T}$ lymphocytes [11, 12], impaired cell-mediated immunity $[4,13]$ and reduced granulocyte and monocyte/macrophage phagocytic function $[4,14,15]$. Iron overload has been shown to be associated with an increased incidence of bacterial infections in patients with and without ESRD $[8,16,17]$, and polymorphonuclear leukocyte (PMN) phagocytic functions appear to be depressed in patients with iron overload [18-22]. With recent implementation of bundling reimbursement policy, the use of intravenous (IV) iron preparations in ESRD patients has dramatically increased [23]. This approach has been adopted by dialysis facilities in an attempt to reduce the cost of anemia treatment by limiting the use of erythropoiesis-stimulating agents (ESA). In many instances, IV iron preparations are administered on a routine basis with insufficient attention to the total body iron stores. In fact, excessive use of IV iron compounds has led to an epidemic of iron overload in the dialysis population [24, 25]. In an elegant study, Deicher et al. [18] evaluated phagocytosis and killing of Escherichia coli before, during, $1 \mathrm{~h}$, and 2 days after IV administration of $300 \mathrm{mg}$ iron sucrose in a group of 10 ESRD patients maintained on peritoneal dialysis. The results were compared to those obtained in 10 placebotreated patients. They found a significant reduction in the absolute count and percentage of E. coli killed by PMNs of the iron sucrose-treated peritoneal dialysis patients over time as compared to values found in the placebotreated patients. These observations provided compelling evidence for the inhibitory action of iron sucrose on neutrophilic granulocytes in this population.

IV iron preparations consist of a core of elemental iron covered by a carbohydrate envelope. In addition to the elemental iron contained in the core of the parenteral iron products, their carbohydrate shell may potentially affect PMNs and monocytes. For instance, it is conceivable that the carbohydrate shell of these products may be detected by the pattern recognition receptors such as toll-like receptor (TLR) 2 and TLR4 expressed on the PMN and monocyte plasma membrane. If true, binding of the complex carbohydrate shell of IV iron products to these receptors can result in activation of PMNs and monocytes and thereby limit or preclude their participation in the phagocytosis and killing of the invading bacteria in vivo or in the in vitro laboratory setting. The present study was designed to examine the effect of one of the commonly used IV iron preparations, iron sucrose, on the phagocytic ca- pacity of PMNs from a group of normal individuals against Gram-positive (Staphylococcus aureus) and Gramnegative (E. coli) bacteria. To this end, iron sucrose was added to heparinized blood samples from each subject at pharmacologically relevant concentrations and incubated for 4 and $24 \mathrm{~h}$ at $37^{\circ} \mathrm{C}$ to simulate in vivo condition. Blood samples mixed with an equal volume of saline solution served as controls. To isolate the possible effect of the complex carbohydrate shell from that of the elemental iron core of the drug, blood samples were simultaneously treated with iron sucrose and the iron chelator, desferrioxamine. In addition to IV iron preparations and iron overload, dialysis procedure, uremic toxins, dialyzer bioincompatibility, underlying illnesses, and the prevailing systemic inflammation can contribute to the PMN dysfunction [26]. We elected to use blood samples from normal individuals to isolate the effect of iron sucrose per se from those of uremic toxins, dialysis-related factors and systemic inflammation. The study showed that iron sucrose causes a significant dose-dependent suppression of phagocytic activities of PMNs against both Gram-positive and Gram-negative bacteria. Iron sucrose-induced suppression of PMN phagocytic activity was prevented by cotreatment with iron chelator, desferrioxamine, thus precluding the contribution of the carbohydrate shell of iron sucrose to the PMN dysfunction. In addition, we compared the extent of apoptosis in blood samples incubated with or without iron sucrose. Iron sucrose significantly increased PMN apoptosis in a dose-dependent manner.

\section{Materials and Methods}

\section{Blood Collection and Study Participants}

Ten healthy individuals, 3 women and 7 men, aged $21-43$ years participated in this study. The study protocol was approved by the Institutional Review Board of the University of California Irvine (HS\# 2007-5572) and completed with the assistance of the University of California, Irvine General Clinical Research Center. Written informed consent was obtained from all subjects. Blood samples were obtained by venipuncture and gently placed into the heparinized tubes and processed as described below. Each blood sample was divided into multiple aliquots to which iron sucrose (American Regent, Inc., Shirley, N.Y., USA) was added to reach the final concentrations of 20,100 and $200 \mathrm{mg} / \mathrm{l}$. The rationale for the choice of these concentrations was based on the anticipated plasma levels following administration of the approved doses of IV iron products considering the blood volume of about 5 liters of which $60-70 \%$ is plasma where the drug is distributed. Given the large size of the iron complex, the distribution of the product is largely limited to plasma. Aliquots mixed with the vehicle served as controls. The samples were then incubated for 4 and $24 \mathrm{~h}$ at $37^{\circ} \mathrm{C}$ in a humidified incubator prior to flow cytometric analysis. 
Assessment of Phagocytosis by Flow Cytomery

The detection of phagocytosis in PMNs was carried out with pHrodo $^{\mathrm{TM}}$ E. coli and pHrodo ${ }^{\mathrm{TM}}$ S. aureus BioParticles Phagocytosis Kits (Invitrogen, Calsbad, Calif., USA). The pHrodo $^{\text {TM }}$ dye becomes fluorescent upon acidification in endocytic compartments, which directly relates to phagocytosis of the labeled particles. pHrodo-labeled E. coli and S. aureus BioParticles ${ }^{\circledR}(20 \mu \mathrm{l})$ were incubated with aliquots of whole peripheral blood that was pretreated with different concentrations of iron. After a 15-min incubation at $37^{\circ} \mathrm{C}$, erythrocytes were lysed, washed with PBS and the samples were analyzed by flow cytometry (FACSCalibur, BD Biosciences). Forward and side scatter was used to gate the PMN and phagocytic uptake was determined by measuring fluorescence signal emitted by endocytosed bacteria. Results are expressed as \% phagocytosis of the control group. CellQuest software was used for analysis (Becton-Dickinson, San Jose, Calif., USA).

Detection of TLR2 or TLR4 Expression by Flow Cytomery

After the incubation for $24 \mathrm{~h}$ at $37^{\circ} \mathrm{C}$ with iron, TLRs were stained using the following antibodies: Alexa Fluor ${ }^{\circledR} 488$-conjugated anti-human TLR2 (eBioscience, San Diego, Calif., USA) and Alexa Fluor ${ }^{\circledR}$ 488-conjugated anti-human TLR4 (eBioscience). Mouse IgG2a K Isotype Control Alexa Fluor ${ }^{\circledR} 488$ (eBioscience) was used as a negative control. The samples were incubated with each antibody in the dark room at $4^{\circ} \mathrm{C}$ for $20 \mathrm{~min}$, and were washed twice with PBS before FACS analysis.

Viability Assessment by Flow Cytomery

Apoptosis was measured using Annexin V-FITC Apoptosis Detection Kit (BioVision). After incubation for $24 \mathrm{~h}$ at $37^{\circ} \mathrm{C}$, the red blood cell contents of the test samples were lysed by ACK lysing, washed, resuspend in annexin binding buffer and stained with FITC-labeled Annexin V and propidium iodide (PI), 50,000 cells from each sample were assessed by flow cytometry (FACSCalibur, Becton-Dickinson). CellQuest software was used for analysis (Becton-Dickinson).

\section{Statistical Analysis}

Student's t test and one-way analysis of variance (ANOVA) were used in statistical analysis of the data using Excel for Windows software (Microsoft, Redmond, Wash., USA). p values $\leq 0.05$ were considered significant. Data are expressed as mean $\pm \mathrm{SD}$.

\section{Results}

\section{Effects of Iron on Phagocytic Function of PMNs}

Incubation with iron sucrose for $4 \mathrm{~h}$ caused a significant concentration-dependent suppression of phagocytic activity of PMNs against $S$. aureus (data are depicted in fig. 1a). Likewise, 4 -hour incubation with iron sucrose caused a significant concentration-dependent inhibition of PMN phagocytic activity against E. coli (data are shown in fig. 1b). Similarly, incubation with iron sucrose for $24 \mathrm{~h}$ resulted in significant reduction of phagocytic function of PMNs against negative bacteria (data are shown in fig. 1c).

To exclude the possible effect of the complex carbohydrate shell from that of the elemental iron core of the drug, blood samples were simultaneously treated with iron sucrose and the iron chelator, desferrioxamine (50 $\mu \mathrm{mol} / \mathrm{l})$. The iron sucrose-induced suppression of PMN phagocytotic activity was completely prevented by desferrioxamine (fig. 2). These findings provide irrefutable evidence for the role of iron core and preclude the contribution of the carbohydrate shell of iron sucrose to the observed PMN dysfunction.

\section{Effects of Iron on TLR2 and TLR4 Expression in PMNs}

TLRs play an essential role in the detection of invading pathogens. TLR2 and TLR4 are expressed on PMNs and serve a critical role in host defenses against Gram-positive and Gram-negative bacteria, respectively. TLR2 recognizes the peptidoglycans on Gram-positive organism, whereas TLR4 recognizes the conserved lipopolysaccharide pattern of Gram-negative bacteria. Exposure to these ligands results in upregulation and activation of these receptors which, in turn, lead to leukocyte activation, cytokine production, and phagocytosis of the given bacteria. We, therefore, asked if the observed suppression of PMN phagocytic function by iron sucrose is associated with and, in part, mediated by changes in TLR 2 and TLR 4 expressions. The study revealed no significant effect on either TLR2 or TLR4 expression on PMN in response to iron sucrose at either 4 or $24 \mathrm{~h}$ (mean fluorescence intensity: control, $20,100 \mathrm{mg} / \mathrm{l}=\mathrm{TLR} 2 ; 61.1 \pm 3.1,58.3 \pm 2.4$, $62.8 \pm 2.8$, TLR4; $22.5 \pm 2.5,23.7 \pm 3.1,25.2 \pm 2.9$, respectively, $\mathrm{p}=\mathrm{NS}$; fig. 3 ).

\section{Effects of Iron Sucrose on PMN Viability and Apoptosis}

Annexin V and PI staining was used to investigate the PMN viability in blood samples incubated with or without iron sucrose for 4 or $24 \mathrm{~h}$. There was no significant difference in Annexin V and PI staining at $4 \mathrm{~h}$. However, iron sucrose resulted in a significantly concentration-dependent increase in the apoptotic PMNs (Annexin V (positive) PI (negative)) (fig. 4). The presence of significant impairment of phagocytic activity of PMNs despite preservation of their viability within the 4-hour exposure to iron sucrose suggests that the inhibitory effect of this compound is independent of its cytocidal action which requires longer exposure. 
Fig. 1. Effect of iron sucrose on phagocytic function in PMNs. The iron sucrose was added to heparinized blood samples from each healthy subject at various concentrations, $0,20,100,200 \mathrm{mg} / \mathrm{l}$ and incubated for 4 and $24 \mathrm{~h}$ at $37^{\circ} \mathrm{C}$. Gram-positive ( $S$. aureus) and Gram-negative (E. coli) bacteria were used for the evaluation of phagocytic function in PMNs. The phagocytic function against Gram-positive and Gramnegative bacteria was evaluated by flow cytometry. a Representative FACS data for phagocytic function against Gram-positive bacteria. $\mathbf{b}$ Phagocytic function against Gram-negative and Gram-positive bacteria after $4 \mathrm{~h}$ incubation with iron sucrose. c Phagocytic function after $24 \mathrm{~h}$ incubation with iron sucrose. ${ }^{*} \mathrm{p}<0.05,{ }^{*} \mathrm{p}<0.01$, *** $\mathrm{p}<0.005$.
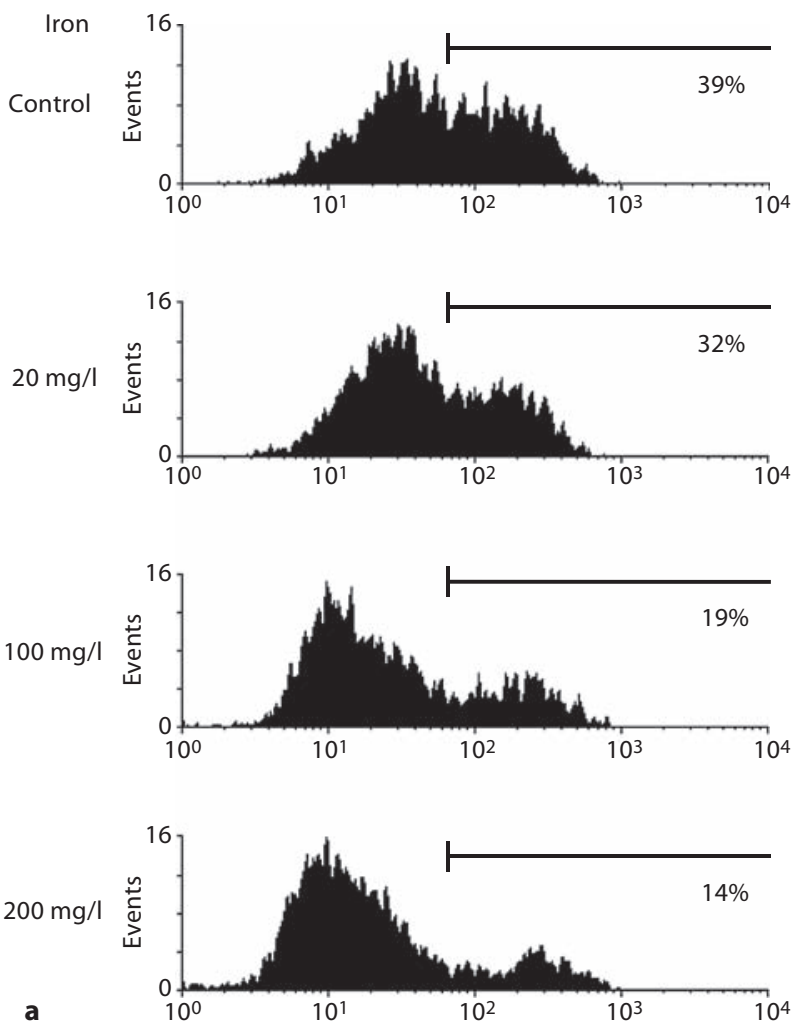

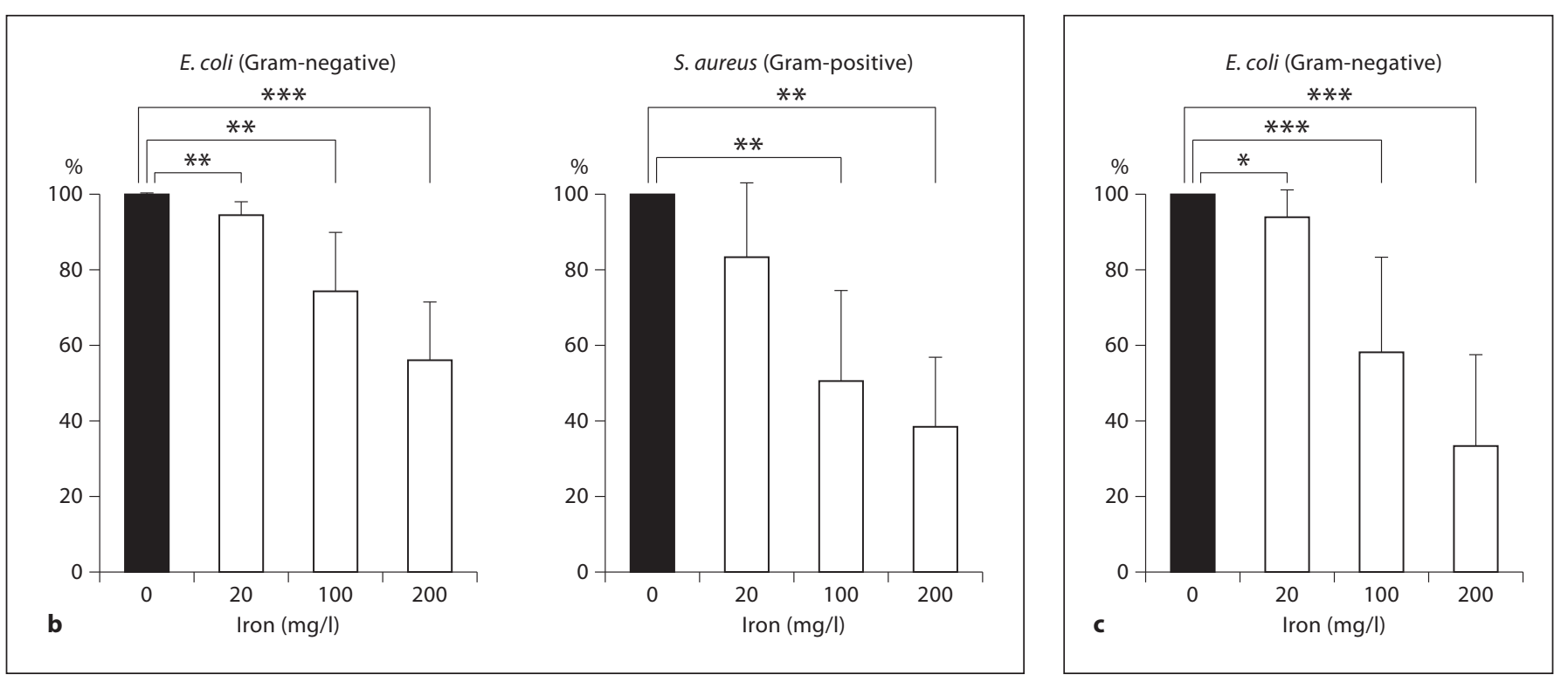

IV Iron-Induced Neutrophil Damage and 


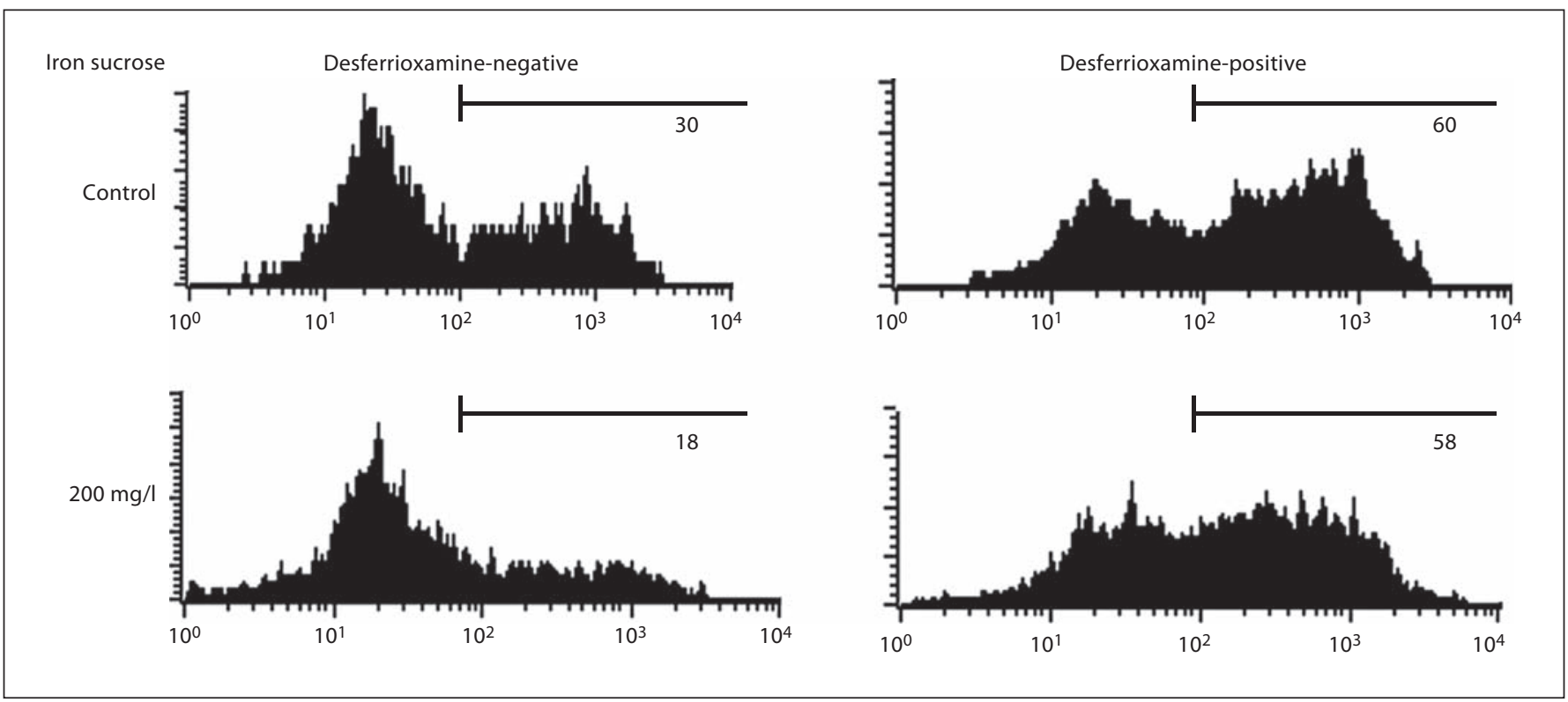

Fig. 2. Prevention of iron sucrose-induced phagocytic dysfunction with desferrioxamine in PMNs. To exclude the possible effect of the complex carbohydrate shell from that of the elemental iron core of the drug, blood samples were simultaneously treated with iron sucrose and the iron chelator, desferrioxamine.

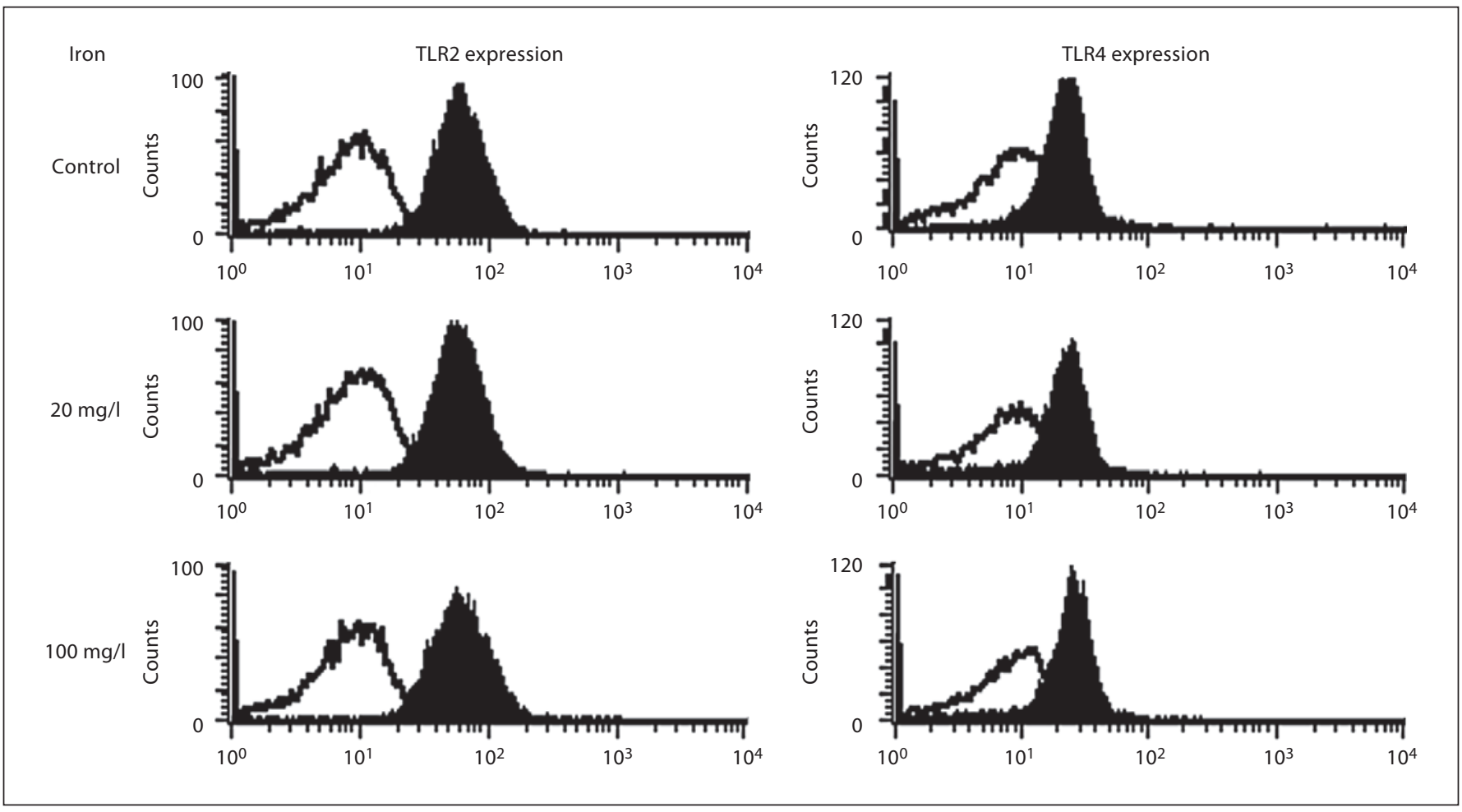

Fig. 3. Effect of iron sucrose on TLR expression in PMNs. The iron sucrose was added to heparinized blood samples from each healthy subject at various concentrations. The TLR2 and TLR4 expressions in PMNs were examined using flow cytometry after 4 or $24 \mathrm{~h}$ incubation with iron sucrose. Black histogram: anti-human TLR2 or TLR4 (positive); white histogram: negative control. 


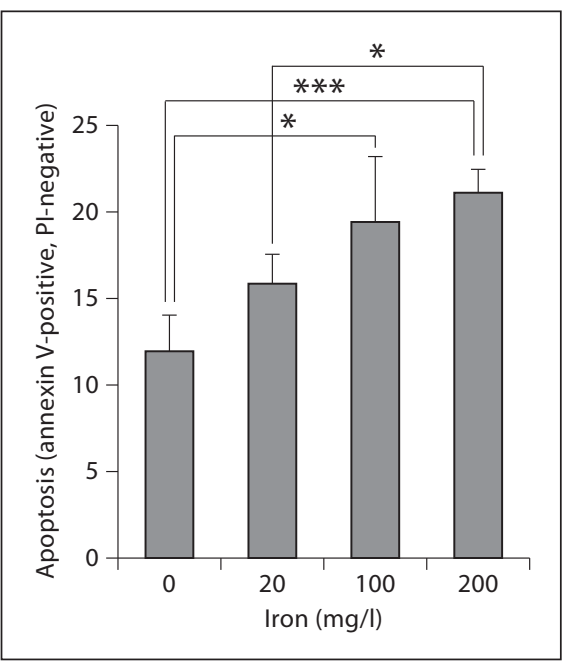

Fig. 4. Effect of iron sucrose on PMNs' viability. The iron sucrose was added to heparinized blood samples from each healthy subject at various concentrations. Annexin-V (positive) PI (negative) population was evaluated as apoptotic PMNs using flow cytometry after $24 \mathrm{~h}$ incubation with iron sucrose. ${ }^{*} \mathrm{p}<0.05$, ${ }^{* * *} \mathrm{p}<$ 0.005 .

\section{Discussion}

The present study showed that pharmacologically relevant concentrations of iron sucrose significantly suppressed the phagocytic function of PMNs from healthy donors in a dose-dependent manner against both Grampositive (S. aureus) and Gram-negative bacteria (E. coli). The molecules expressed on the wall of Gram-positive bacterial (peptidoglycans) and Gram-negative bacteria (lipopolysaccharides) are recognized by pattern recognition receptors, TLR2 and TLR4, respectively. These receptors are expressed on PMNs, monocytes, and macrophages. Exposure to these ligands results in upregulation and activation of these receptors which, in turn, lead to leukocyte activation, cytokine production, and phagocytosis of the given bacteria. To explore the possibility that iron sucrose-induced suppression of phagocytic activity of PMNs against Gram-positive and Gram-negative bacteria is mediated by modulation of TLR 2 or TLR4 expression, we examined the expression of these receptors on PMNs in blood samples incubated with iron sucrose. The experiments revealed no significant change in either TLR2 or TLR4 expression in PMNs with this iron preparation.

To dissect the contribution of iron core from the carbohydrate shell of iron sucrose to the observed suppres- sion of PMNs' phagocytic activity, we examined the effect of co-incubation of blood samples with iron sucrose and iron chelator, desferrioxamine. Co-treatment with iron chelator prevented the suppression of phagocytic function in PMNs by iron sucrose. This observation excluded the possible contribution of the carbohydrate shell of iron sucrose to the PMN dysfunction. We next asked if iron sucrose affects the viability of PMNs. To this end, we compared the extent of apoptosis in blood samples incubated with or without iron sucrose. The experiments showed a significant dose-dependent increase in PMN apoptosis with iron sucrose. This observation points to the injurious effect of iron sucrose on PMNs which may, in part, account for the observed impairment of their phagocytic activity.

Phagocytosis is a major component of the host defense against microbial infection. Consequently, inhibition of phagocytic activity of PMNs by iron sucrose can contribute to an increased incidence and severity and poor outcome of bacterial infections in patients treated with excessive dose of this and other IV iron preparations. Besides suppression of phagocytic function of PMNs, iron overload can increase susceptibility to and severity of bacterial infections by promoting growth and enhancing virulence of bacteria $[27,28]$. In order to acquire iron, bacteria compete with the host for the available iron by secreting low-molecular-weight iron chelators known as siderophores. These siderophores avidly bind free iron to form iron complexes which are taken up by microbe via receptor-mediated endocytosis [29, 30]. Under normal conditions nearly all of the plasma iron content is bound to transferrin which makes it inaccessible to the bacteria [27]. Administration of IV iron preparations results in rapid saturation of plasma transferrin and the rise in catalytically active non-transferrin-bound iron in the plasma, thereby providing readily accessible iron for bacteria. Thus, IV iron preparations may not only suppress the host's innate immune response but also increase the potential risk of infection. Interestingly, $S$. aureus possesses a transferrin receptor that allows it to acquire iron available in the bloodstream [29].

The deleterious effect of iron sucrose on phagocytic activity in PMNs was compounded by the increased PMN apoptosis. This is most likely due to iron-induced oxidative stress in these cells. It should be noted that when compared to the intestinal absorption of 1-2 mg iron in the course of 3 meals per day, rapid IV infusion of large quantities of iron (100-1,000 mg) within a few minutes represents an enormous load with which the body is not accustomed. In fact, administration of these products has 
been shown to result in appearance of catalytically active non-transferrin-bound iron and a rise in markers of oxidative stress and inflammation in dialysis patients [3135]. This is compounded by elevation of plasma hepcidin [36] which renders the ESRD patients particularly susceptible to the adverse effects of intravenously administered iron preparations especially when used indiscriminately. This is because by blocking ferroportin which is the main pathway of iron export in the macrophages and other reticuloendothelial cells, elevation of hepcidin leads to trapping and rapid expansion of iron pool in these cells. IV sucrose consists of a core of elemental iron covered by a carbohydrate envelope. Following their IV administration, these products are taken up by the reticuloendothelial cells which remove and release their carbohydrate moiety for clearance by the liver. The iron core is then used for storage in ferritin and release for binding to transferrin [37]. However, due to their massive load and rapid introduction, administration of these products leads to elevated levels of catalytically active iron within the cells and non-transferrin-bound iron in the plasma [38]. This leads to formation of iron-catalyzed hydroxyl radical and oxidative stress which can account for the PMN apoptosis observed in the present study [3943].

The results of the present in vitro study, which demonstrated a concentration-dependent suppression of PMN phagocytic capacity and viability by iron sucrose, parallel the findings of an earlier cross-sectional investigation of ESA- and IV iron-treated ESRD patients reported by Patruta et al. [22]. These investigators examined the phagocytic and bacteriocidal properties of PMN from subgroups of patients with a wide range of serum ferritin levels $(<60$ to $>650 \mu \mathrm{g} / \mathrm{l})$ against $E$. coli and found a sig- nificant association between ferritin level and impairment of PMN functions in hemodialysis patients. Based on these observations they cautioned against excessive use of IV iron in hemodialysis patients with elevated ferritin levels.

\section{Conclusions}

The results showed that iron sucrose at pharmacologically relevant concentrations significantly inhibits phagocytic function in PMNs against both Gram-positive and Gram-negative bacteria, and that the deleterious effect of iron sucrose was mediated by its elemental iron core but not its carbohydrate shell and as such may be shared by other IV iron preparations. Furthermore, iron sucrose significantly increased PMN apoptosis which may, in part, account for the observed impairment of their phagocytic activity. These findings build upon previous studies and provide compelling evidence for the potential adverse effects of the indiscriminate use of the IV iron preparations in the highly vulnerable patients with advanced CKD.

\section{Acknowledgments}

This work was supported in part by NIH-NCRR UL1 TR000153, KL2 TR000147 and the Juvenile Diabetes Research Foundation International 17-2011-609.

\section{Disclosure Statement}

The authors have no conflicts of interest to disclose.

\section{References}

1 Girndt M, Sester U, Sester M, et al: Impaired cellular immune function in patients with end-stage renal failure. Nephrol Dial Transplant 1999;14:2807-2810.

2 United States Renal Data System (USRDS): Annual Data Report. Bethesda, National Institutes of Health, Diabetes and Digestive and Kidney Diseases, 1998.

-3 Sarnak MJ, Jaber BL: Mortality caused by sepsis in patients with end-stage renal disease compared with the general population. Kidney Int 2000;58:1758-1764.

-4 Girndt M, Sester M, Sester U, et al: Molecular aspects of T- and B-cell function in uremia. Kidney Int Suppl 2001;78:S206-S211.
5 Sester U, Sester M, Hauk M, et al: T-cell activation follows Th1 rather than Th2 pattern in haemodialysis patients. Nephrol Dial Transplant 2000;15:1217-1223.

-6 Meuer SC, Hauer M, Kurz P, et al: Selective blockade of the antigen-receptor-mediated pathway of T-cell activation in patients with impaired primary immune responses. J Clin Invest 1987;80:743-749.

7 Agrawal S, Gollapudi P, Elahimehr R, et al: Effects of end-stage renal disease and haemodialysis on dendritic cell subsets and basal and LPS-stimulated cytokine production. Nephrol Dial Transplant 2010;25:737-746.
-8 Boelaert JR, Daneels RF, Schurgers ML, et al: Iron overload in haemodialysis patients increases the risk of bacteraemia: a prospective study. Nephrol Dial Transplant 1990;5:130134.

9 Smogorzewski M, Massry SG: Defects in Bcell function and metabolism in uremia: role of parathyroid hormone. Kidney Int Suppl 2001;78:S186-S189.

10 Pahl MV, Gollapudi S, Sepassi L, et al: Effect of end-stage renal disease on B-lymphocyte subpopulations, IL-7, BAFF and BAFF receptor expression. Nephrol Dial Transplant 2010;25:205-212. 
11 Matsumoto Y, Shinzato T, Amano I, et al: Relationship between susceptibility to apoptosis and Fas expression in peripheral blood $\mathrm{T}$ cells from uremic patients: a possible mechanism for lymphopenia in chronic renal failure. Biochem Biophys Res Commun 1995; 215:98-105.

12 Yoon JW, Gollapudi S, Pahl MV, Vaziri ND: Naive and central memory T-cell lymphopenia in end-stage renal disease. Kidney Int 2006; 70:371-376.

13 Moser B, Roth G, Brunner M, et al: Aberrant T-cell activation and heightened apoptotic turnover in end-stage renal failure patients: a comparative evaluation between non-dialysis, haemodialysis, and peritoneal dialysis. Biochem Biophys Res Commun 2003;308: 581-585.

-14 Alexiewicz JM, Smogorzewski M, Fadda GZ, Massry SG: Impaired phagocytosis in dialysis patients: studies on mechanisms. Am J Nephrol 1991;11:102-111.

15 Massry S, Smogorzewski M: Dysfunction of polymorphonuclear leukocytes in uremia: role of parathyroid hormone. Kidney Int Suppl 2001;78:S195-S196.

16 Green NS: Yersinia infections in patients with homozygous $\beta$-thalassemia associated with iron overload and its treatment. Pediatr Hematol Oncol 1992;9:247-254.

$\checkmark 17$ Hoen B, Kessler M, Hestin D, Mayeux D: Risk factors for bacterial infections in chronic haemodialysis adult patients: a multicentre prospective survey. Nephrol Dial Transplant 1995;10:377-381.

18 Deicher R, Ziai F, Cohen G, et al: High-dose parenteral iron sucrose depresses neutrophil intracellular killing capacity. Kidney Int 2003;64:728-736

19 Van Asbeck BS, Marx JJ, Struyvenberg A, Verhoef J: Functional defects in phagocytic cells from patients with iron overload. J Infect 1984;8:232-240.

20 Waterlot Y, Cantinieaux B, Hariga-Muller C, et al: Impaired phagocytic activity of neutrophils in patients receiving haemodialysis: the critical role of iron overload. Br Med J (Clin Res Ed) 1985;291:501-504.
21 Veys N, Vanholder R, Ringoir S: Correction of deficient phagocytosis during erythropoietin treatment in maintenance hemodialysis patients. Am J Kidney Dis 1992;19:358-363.

22 Patruta SI, Edlinger R, Sunder-Plassmann G, Horl WH: Neutrophil impairment associated with iron therapy in hemodialysis patients with functional iron deficiency. J Am Soc Nephrol 1998;9:655-663.

23 Freburger JK, Ng LJ, Bradbury BD, Kshirsagar AV, Brookhart MA: Changing patterns of anemia management in US hemodialysis patients. Am J Med 2012 (in press).

24 Vaziri ND: Epidemic of iron overload in dialysis population caused by excessive use of intravenous iron products: a plea for moderation. Am J Med 2012 (in press).

25 Rostoker G, Griuncelli M, Christelle L, et al: Hemodialysis-associated hemosiderosis in the era of erythropoiesis-stimulating agents. Am J Med 2012 (in press).

26 Chonchoi M: Neutrophiol dysfunction and infection risk in end-stage renal disease. Semin Dial 2006;19:291-296.

27 Bullen JJ: The significance of iron in infection. Rev Infect Dis 1981;3:1127-1138.

28 Ward CG, Hammond JS, Bullen JJ: Effect of iron compounds on antibacterial function of human polymorphs and plasma. Infect Immun 1986;51:723-730.

29 Williams P, Griffiths E: Bacterial transferrin receptors - structure, function and contribution to virulence. Med Microbiol Immunol 1992;181:301-322.

30 Fishbane S: Review of issues relating to iron and infection. Am J Kidney Dis 1999;34:S47S52.

-31 Agarwal R: Proinflammatory effects of iron sucrose in chronic kidney disease. Kidney Int 2006;69:1259-1263.

32 Agarwal R, Vasavada N, Sachs NG, Chase S: Oxidative stress and renal injury with intravenous iron in patients with chronic kidney disease. Kidney Int 2004;65:2279-2289.

33 Anirban G, Kohli HS, Jha V, et al: The comparative safety of various intravenous iron preparations in chronic kidney disease patients. Ren Fail 2008;30:629-638.
34 Ganguli A, Kohli HS, Khullar M, et al: Lipid peroxidation products formation with various intravenous iron preparations in chronic kidney disease. Ren Fail 2009;31:106-110.

35 Maruyama Y, Nakayama M, Yoshimura K, et al: Effect of repeated intravenous iron administration in haemodialysis patients on serum 8-hydroxy-2'-deoxyguanosine levels. Nephrol Dial Transplant 2007;22:1407-1412.

36 Nakanishi T, Hasuike Y, Otaki Y, et al: Hepcidin: another culprit for complications in patients with chronic kidney disease? Nephrol Dial Transplant 2011;26:3092-3100.

- 37 Macdougall IC: Intravenous administration of iron in epoetin-treated haemodialysis patients - which drugs, which regimen? Nephrol Dial Transplant 2000;15:1743-1745.

38 Slotki I: Intravenous iron supplementation in the anaemia of renal and cardiac failure - a double-edged sword? Nephrol Dial Transplant 2005;20(suppl 7):vii16-vii23.

-39 Salahudeen AK, Oliver B, Bower JD, Roberts LJ 2nd: Increase in plasma esterified $\mathrm{F}_{2}$-isoprostanes following intravenous iron infusion in patients on hemodialysis. Kidney Int 2001;60:1525-1531.

-40 Tovbin D, Mazor D, Vorobiov M, et al: Induction of protein oxidation by intravenous iron in hemodialysis patients: role of inflammation. Am J Kidney Dis 2002;40:10051012.

41 Guz G, Glorieux GL, De Smet R, et al: Impact of iron sucrose therapy on leucocyte surface molecules and reactive oxygen species in haemodialysis patients. Nephrol Dial Transplant 2006;21:2834-2840.

42 Pai AB, Boyd AV, McQuade CR, et al: Comparison of oxidative stress markers after intravenous administration of iron dextran, sodium ferric gluconate, and iron sucrose in patients undergoing hemodialysis. Pharmacotherapy 2007;27:343-350.

-43 Kuo KL, Hung SC, Wei YH, Tarng DC: Intravenous iron exacerbates oxidative DNA damage in peripheral blood lymphocytes in chronic hemodialysis patients. J Am Soc Nephrol 2008;19:1817-1826. 